\title{
Risk of lung cancer associated with domestic use of coal in Xuanwei, China: retrospective cohort study
}

\author{
(c) $\frac{(1)(8)}{\text { gy }}$ OP OPEN ACCESS
}

\author{
Francesco Barone-Adesi postdoctoral fellow ${ }^{1}$, Robert S Chapman lecturer ${ }^{2}$, Debra T Silverman \\ senior investigator ${ }^{1}$, Xinghzhou He professor ${ }^{3}$, Wei Hu postdoctoral fellow ${ }^{1}$, Roel Vermeulen assistant \\ professor $^{4}$, Bofu Ning scientist ${ }^{5}$, Joseph F Fraumeni Jr senior investigator ${ }^{1}$, Nathaniel Rothman \\ senior investigator ${ }^{1}$, Qing Lan senior investigator ${ }^{1}$
}

${ }^{1}$ Division of Cancer Epidemiology and Genetics, National Cancer Institute, NIH, DHHS, 6120 Executive BIv, EPS 8015, Bethesda, MD 20892-7240, USA; ${ }^{2}$ College of Public Health Sciences, Chulalongkorn University, Pathumwan, Bangkok 10330, Thailand; ${ }^{3}$ Institute of Environmental Health and Engineering, Chinese Academy of Preventive Medicine, Beijing 100050, China; ${ }^{4}$ Institute for Risk Assessment Sciences, Division of Environmental Epidemiology, Utrecht University, 3584 CK Utrecht, Netherlands; ${ }^{5}$ Xuanwei Center of Disease Control No 6, Xuanwei, Qujing, Yunnan 655400 PR China

\begin{abstract}
Objective To estimate the risk of lung cancer associated with the use of different types of coal for household cooking and heating.

Setting Xuanwei County, Yunnan Province, China.

Design Retrospective cohort study (follow-up 1976-96) comparing mortality from lung cancer between lifelong users of "smoky coal" (bituminous) and "smokeless coal" (anthracite).

Participants 27310 individuals using smoky coal and 9962 individuals using smokeless coal during their entire life.

Main outcome measures Primary outcomes were absolute and relative risk of death from lung cancer among users of different types of coal. Unadjusted survival analysis was used to estimate the absolute risk of lung cancer, while Cox regression models compared mortality hazards for lung cancer between smoky and smokeless coal users.

Results Lung cancer mortality was substantially higher among users of smoky coal than users of smokeless coal. The absolute risks of lung cancer death before 70 years of age for men and women using smoky coal were $18 \%$ and $20 \%$, respectively, compared with less than $0.5 \%$ among smokeless coal users of both sexes. Lung cancer alone accounted for about $40 \%$ of all deaths before age 60 among individuals using smoky coal. Compared with smokeless coal, use of smoky coal was associated with an increased risk of lung cancer death (for men, hazard ratio 36 (95\% confidence interval 20 to 65); for women, 99 (37 to 266)).

Conclusions In Xuanwei, the domestic use of smoky coal is associated with a substantial increase in the absolute lifetime risk of developing lung cancer and is likely to represent one of the strongest effects of
\end{abstract}

environmental pollution reported for cancer risk. Use of less carcinogenic types of coal could translate to a substantial reduction of lung cancer risk.

\section{Introduction}

About half of the world's population uses unprocessed biomass fuels and coal for cooking and heating. ${ }^{1}$ Exposure to solid fuel smoke is associated with several diseases, including chronic obstructive pulmonary disease, acute respiratory infections, and cancer, particularly lung cancer. ${ }^{2}$ Recently, the International Agency for Research on Cancer (IARC) classified emissions from indoor combustion of coal as carcinogenic to humans (group 1) on the basis of sufficient evidence in both humans and animals. ${ }^{3}$ The risk of lung cancer associated with household coal burning shows substantial heterogeneity by geographical location, due to the use of different coal types. ${ }^{245}$

Although China is urbanising rapidly, more than $60 \%$ of the population is still rural. Most households in rural areas still burn biomass fuel such as wood, crop residues, or coal in simple stoves that are often unvented and that produce substantial indoor air pollution. ${ }^{6}$ According to a large survey, in 1993 about $70 \%$ of the population in rural China used coal for cooking. ${ }^{7}$ Household use of solid fuels is estimated to be the largest single environmental risk factor in China and ranks sixth among all risk factors contributing to poor health in this country. ${ }^{6}$ Lung cancer rates in Xuanwei County, Yunnan Province, south western China, are among the country's highest. In contrast, lung cancer rates in Yunnan Province as a whole are low, even 
in relation to the Chinese national average rate. ${ }^{8}$ Rates in Xuanwei are similar for men and women, even though almost all women are non-smokers. ${ }^{2}$

Xuanwei residents have traditionally used at least one of three different types of fuel for household cooking and heating: "smoky coal" (bituminous), "smokeless coal" (anthracite), and wood. Polycyclic aromatic hydrocarbons (PAHs), methylated PAHs, and nitrogen-containing heterocyclic aromatic compounds are found in abundance in the particles emitted from smoky coal combustion. ${ }^{8-10}$ A survey conducted in 1995 reported average levels of indoor air pollution during unvented and vented smoky coal burning in study area homes. ${ }^{11}$ Levels of air pollution during vented burning were much lower than during unvented burning. Average concentrations of $\mathrm{PM}_{10}$ particulates and benzo(a)pyrene during vented burning $\left(0.71 \mathrm{mg} / \mathrm{m}^{3}\right.$ and $0.25 \mu \mathrm{g} / \mathrm{m}^{3}$ ) were, respectively, only $34.1 \%$ and $15.1 \%$ of corresponding concentrations during unvented burning (2.08 $\mathrm{mg} / \mathrm{m}^{3}$ and $\left.1.66 \mu \mathrm{g} / \mathrm{m}^{3}\right) .{ }^{11}$ Toxicological studies have shown that combustion products of the smoky coal used in Xuanwei are more tumorigenic and mutagenic than the products of smokeless coal and wood. ${ }^{9}{ }^{10}$ The weight of available evidence indicates that indoor burning of smoky coal causes lung cancer in Xuanwei. ${ }^{2} 3811$ An ecological study showed an association between the proportion of households reporting use of smoky coal and lung cancer mortality in the different communes of Xuanwei. $^{8}$

We previously reported in a case-control study of lung cancer in Xuanwei that lung cancer risk was up to 30-fold higher among users of smoky coal than among users of smokeless coal and wood. ${ }^{2}$ However, the relationship between smoky coal use and lung cancer is not fully understood. A thorough quantitative assessment of the health effects of lifelong use of different types of coal could have important public health implications and lend support to the introduction of further preventive measures.

The Xuanwei cohort study is a large retrospective cohort study, which has previously been used to assess the long term health benefits of converting from unvented stoves to stoves with chimneys or portable stoves. ${ }^{11-14}$ The cohort design allowed us to estimate for the first time the absolute risk of lung cancer among users of different types of coal. Moreover, we evaluated the role of several time related variables associated with household exposure to coal combustion products (namely average number of hours per day spent indoors at home, and age at starting cooking) on the risk of lung cancer.

\section{Methods \\ Data collection}

The characteristics of the study cohort are reported in detail elsewhere. ${ }^{11}{ }^{14}$ Briefly, the study area comprised four communes in the Xuanwei County (Rongcheng, Laibin, Jingwai, and Reshui). Local administrative records identified all residents in this area as of 1 January 1976 and born between 1917 and 1951. A total of 42422 individuals were available for the study, after 2108 individuals who had moved out of the study area and 50 individuals who provided insufficient information for the analysis were excluded.

In 1992 trained interviewers administered a standardised questionnaire to all cohort members. They interviewed participants directly when feasible; surrogate respondents were used when individuals were dead or not present $(41 \%$ of participants). The questionnaire elicited information regarding demographic factors, residential history, lifetime use of household stove and fuel type, occupational history, ever having smoked any form of tobacco regularly, cooking practices, time spent indoors and outdoors, medical history, and family history of lung cancer. This study was approved by the Institutional Review Board of the Chinese Academy of Preventive Medicine. Signed informed consent was obtained from all literate respondents. Study procedures were explained orally to each illiterate prospective subject in the presence of a literate relative. If the subject gave oral consent, the relative signed the consent form as a proxy.

The dates of all deaths in the cohort from 1 January 1976 to 31 December 1996 were abstracted from death records. The causes of death were coded by the Xuanwei Center for Disease Control according to ICD-9 (international classification of diseases, ninth revision) ${ }^{15}$ Records from six hospitals were also searched to identify incident cases of lung cancer in cohort members from 1976 through 1992. Four hospitals were in Xuanwei. One of these, the Xuanwei County Hospital, accounted for more than $90 \%$ of the county's hospitalisations. Records from the Qujing District Hospital and the Yunnan Province Hospital were also searched.

\section{Data analysis}

The analysis in this paper was restricted to individuals who used either smoky or smokeless coal and did not change fuel type throughout their lifetime. This restriction excluded 5150 individuals, leaving 37272 participants.

The sex specific absolute risks of death from any cause, from lung cancer, and from non-neoplastic respiratory diseases were plotted against age for smoky and smokeless coal users. The cumulative incidence functions, accounting for the presence of competing risks, were calculated using the method described by Coviello and Boggess. ${ }^{16}$ Absolute risks among smoky and smokeless coal users were compared using the statistical test of Pepe and Mori. ${ }^{17}$ Age standardised lung cancer mortality was also calculated, stratified by sex, type of coal used, and smoking status.

Multivariable Cox regression models were constructed to compare mortality hazards for lung cancer (ICD-9 code 162) between smoky and smokeless coal users. Attained age was chosen as the time axis in the main analyses. In most cohort studies the effect of age needs to be tightly controlled because the incidence of most diseases, especially chronic diseases, is strongly associated with age. The most logical time scale is therefore (attained) age. Using time-on-study as the time scale would generally be less incisive than using age, especially when entry into the cohort coincides with an interview, which would not be expected to influence one's risk. Even so, we also conducted a sensitivity analysis using time-on-study as the time axis and including attained age as a covariate in the models.

Unlike in the univariable analysis, deaths due to any cause other than lung cancer were treated as censored observations in the Cox models. Cox models for both sexes included indicator variables for the following: (1) type of coal used (smoky or smokeless coal); (2) type of stove used (stoves without chimney, stoves with chimney, portable stoves), treated as a time dependent variable to allow for changes in the stoves over lifetime of the subject); (3) having any formal education; (4) history of lung cancer in the subject's parents, siblings, or children; (5) and reported diagnosis of chronic bronchitis, emphysema, or tuberculosis. Average number of waking hours spent indoors at home, number of rooms in the home, and number of people living in the home during the subject's lifetime were included in the model as time dependent variables as well. Models restricted to men also included smoking history as a 
time dependent dichotomous variable (never smoker or ever smoker of any kind of tobacco) and a variable indicating whether the subject was ever a coal miner. The women's models included the age at which the participant started cooking. All models were stratified by birth cohort (1917-21, 1922-26, 1927-31, 1932-36, 1937-41, 1942-46, and 1947-51). The assumption of proportional hazards was evaluated by means of graphical checks on the log cumulative hazard for each covariate and a formal test based on Schoenfeld residuals. ${ }^{18}$ No violation of the proportional hazards assumption was observed.

Several secondary analyses were conducted to further evaluate the association between exposure to smoky coal and risk of lung cancer. First, to evaluate the role of a possible misclassification of the outcome, Cox regression analysis was replicated using incident lung cancer cases and restricting the analysis to the period 1976-92. The analyses were conducted using all incident cases first, then including only cases with cytological or histological confirmation of the diagnosis, and finally excluding incident cases of lung cancer that did not die within two years after the diagnosis. Second, to evaluate the possible role of recall bias among the surrogate responders, mortality analysis was restricted to individuals who were alive at the time of the interview.

Specific analyses were conducted to evaluate the role of different temporal patterns of exposure to emissions from smoky coal on the risk of lung cancer. The average number of hours per day spent indoors at home (excluding sleeping) was used as a proxy for the daily intensity of exposure (resultant of indoor air concentration and the time spent indoors). The age at which the participant started cooking was used as a proxy for the commencement of direct exposure to emissions during cooking. Natural cubic splines were incorporated into the Cox models to assess the shape of the exposure-response relationships and allow for possible non-linear effects. The optimal degree of smoothing was chosen using a model selection procedure proposed by Royston and Sauerbrei. ${ }^{19}$

The results of the Cox analyses are expressed in terms of estimated hazard ratios and $95 \%$ confidence intervals. Analyses were performed with the software Stata 11 (StataCorp, College Station, TX, USA).

\section{Results}

Table $1 \Downarrow$ presents the characteristics of the 37272 individuals included in the study, of whom 73\% (14 232 men and 13078 women) used smoky coal as fuel type during their lifetime. Smoky coal users and smokeless coal users were similar with regard to most of the known or suspected risk factors for lung cancer (table $1 \Downarrow$ ). More than $90 \%$ of the men (18 133 men) and less than $1 \%$ of the women (51 women) in both groups had ever smoked any type of tobacco. The average numbers of cigarettes smoked each day among smokers in the smoky coal and smokeless coal groups were 8.4 and 7.5 respectively. Almost $98 \%$ of the women (17 268 women) and less than $10 \%$ of the men (1688 men) in the two groups cooked food for the family. About $50 \%$ of the men (9206 men) and $25 \%$ of the women (4351 women) had some education. More than $80 \%$ of the participants (31 527 individuals) in both groups reported improvement of the stoves used in their houses (from unvented stoves to stoves with chimney or portable stoves) during their lifetime.

There were 8976 deaths during the study period, 2377 from lung cancer. Fig $1 \Downarrow$ shows the results of the unadjusted survival analysis. In both sexes, the age specific probabilities of dying from any cause and from lung cancer were significantly higher
$(\mathrm{P}<0.001)$ for individuals who used smoky coal than for those who used smokeless coal. The median ages at death were 3 and 6 years younger among men and women using smoky coal, respectively, than among those of the same sex using smokeless coal. After adjustment for the presence of competing risks, the probability of death due to lung cancer before 70 years of age for men and women using smoky coal was $18 \%$ and $20 \%$, respectively, whereas it was less than $0.5 \%$ among individuals of both sexes using smokeless coal (fig $1 \Downarrow$ ). Lung cancer alone accounted for about $40 \%$ of deaths before age 60 among individuals using smoky coal (fig 1). The absolute risk of death from lung cancer was similar among smoky coal users of both sexes even though the prevalence of smoking was much higher among men than among women. The effect of smoking was further investigated by comparing age standardised lung cancer mortality stratified by sex, smoking status, and type of coal used (table $2 \Downarrow$ ). The lung cancer rates were higher among smoky coal users than among smokeless coal users irrespective of sex and smoking habit.

Table $3 \Downarrow$ summarises the results of the main Cox models. After adjustment for potential confounders, lifelong use of smoky coal compared with smokeless coal use was associated with a 36-fold increase of lung cancer mortality in men and a 99-fold increase in women. An increase in lung cancer risk was also observed among smoky coal users when we used data on incidence of lung cancer in the analysis instead of mortality data (for men, hazard ratio 32.1 (95\% confidence interval 17.0 to 60.7); for women, hazard ratio 54.0 (22.2 to 131)). Further restricting the analysis to incident cases with cytological or histological confirmation of the diagnosis did not appreciably change the results (for men, 45.7 (18.6 to 112); for women, 49.5 (15.6 to 157)). Similar results were also found when we excluded from the analysis participants with incident lung cancer who did not die within two years after the diagnosis (for men, 25.7 (13.1 to 50.6); for women, 62.9 (20.0 to 198)). Also restricting mortality analysis to individuals who were alive at the time of the interview did not change the results appreciably among men (hazard ratio 35.9 (8.58 to 150.5$)$ ). No such analysis was possible for women, as no case was observed among women using smokeless coal who were alive at the time of the interview. Changing the time axis of the analysis and including age as a covariate did not change the results (hazard ratio for men 38 , for women 96). Alternative strategies to adjust for the effect of smoking using duration of exposure or intensity of exposure (number of cigarettes per day) did not change the results either (results not shown). No significant effect modification by birth cohort was observed $(\mathrm{P}=0.3)$.

Fig $2 \Downarrow$ shows the relation between the average number of hours spent at home every day (excluding sleeping) and lung cancer mortality among users of smoky coal. Both men and women exhibited a similar pattern, with a monotonically increasing risk that became evident for individuals who spent more than 10 hours a day at home. Fig $3 \Downarrow$ shows the relation between the age at which participants started cooking and lung cancer mortality among women who used smoky coal. No such analysis was possible for men because only a small proportion of men in the cohort cooked. The risk of lung cancer declined steadily with increasing age at which participants started cooking.

\section{Discussion}

In an analysis based on more than 2000 deaths from lung cancer in Xuanwei, China, we found that incidence of and mortality from lung cancer were substantially higher among users of smoky coal in their household stoves than among users of 
smokeless coal. We also found a positive association between the average number of hours that a smoky coal user spent at home and lung cancer mortality. An inverse association between the age at which participants started cooking and lung cancer mortality was also observed.

Absolute risks of death from lung cancer of $18 \%$ and $20 \%$ were found among men and women using smoky coal. These risks are almost as high as those reported for heavy smokers in Western countries, ranging between $20 \%$ and $26 \%{ }^{20}{ }^{21}$ In Cox regression models, lifelong use of smoky coal compared with smokeless coal was associated with a 36-fold increase in lung cancer mortality in men and a 99-fold increase in women. This difference of effect between men and women is mainly due to the sex difference in lung cancer mortality among smokeless coal users (see table $2 \Downarrow$ ). Lung cancer mortality among smoky coal users was similar regardless of sex and smoking status (table 2). This observation is consistent with the hypothesis that, with exposure to high levels of airborne carcinogens such as those produced by the combustion of smoky coal, smoking could exert only a weak additional influence on lung cancer risk. ${ }^{22}$ The low rates of lung cancer observed in the smokeless coal group were consistent with the low rates of lung cancer in Yunnan Province as compared with the national average. ${ }^{8}$ The reasons why Yunnan Province has low rates of lung cancer are not clear but could be in part related to relatively low levels of cigarette smoking in the Yunnan population. ${ }^{23}{ }^{24}$ The smoking patterns in our cohort (8.4 and 7.5 cigarettes smoked per day among smokers in the smoky coal and smokeless coal groups, respectively) are consistent with those of the Yunnan population as a whole.

We found a positive association between time spent indoors at home and risk of lung cancer, which is consistent with a previous observation in a report that included part of this study population. ${ }^{11}$ Although this association is relatively clear (fig $2 \Downarrow$ ) its interpretation is not straightforward. The extent to which the average number of hours per day spent indoors at home can be considered a good proxy for the average intensity of exposure to emissions from smoky coal depends on the assumption that the levels of exposures in the houses are similar after adjusting for some characteristics of the dwelling (type of stove used and number of rooms in the house). Possible violations of this assumption would probably introduce non-differential misclassification of the exposure, resulting in an attenuation of the association. It could be also questioned whether the time spent indoors is associated with the time spent cooking. However, it should be noted that that the shape of the association was almost identical for men and women, and only a small proportion of men cooked (fig $2 \Downarrow$ ). For this reason, the observed association between time spent indoor at home and risk of lung cancer seems to be at least partially independent from being engaged in cooking.

We used the age at which participants started cooking as a proxy for the start of exposure to emissions from smoky coal during cooking. As all the models used in the present analyses were inherently adjusted by attained age, we could not include age at starting cooking and duration of cooking together in the models because of collinearity. Thus, the inverse association observed (see fig $3 \Downarrow$ ) could be due to a positive association between duration of cooking and risk of lung cancer or a higher susceptibility to exposures during cooking at a younger age, or a combination of both.

\section{Strengths and limitations of the study}

Our analysis has several strengths. Firstly, we were able to compare individuals exposed to a single type of coal for their entire lifetime. The detailed information obtained through the questionnaire also allowed us to account for the roles of several possible confounders in the analysis, such as smoking, occupation, education, family history of lung cancer, a previous diagnosis of chronic respiratory diseases, and type of stove used in the household.

One possible limitation of the study is potential recall bias related to surrogate respondents. As most of the participants with lung cancer were dead at the time of the interview, their information was gathered through surrogate responders, which could have introduced recall bias. However, analyses using data only from participants who were alive at the time of the interview were consistent with the results of the primary analysis, suggesting a small effect, if any, from recall bias. Moreover, since this is a rural area, the population is stable. Most participants lived in one to two residences over their lifetime, so differential recall of coal source seems improbable.

There is some evidence that during the 1970s lung cancer may have been under-diagnosed in rural China. ${ }^{7}$ For example, it is possible that some cases of lung cancer could have been misdiagnosed as other types of respiratory disease. As such, it is possible that the absolute risks from lung cancer in the cohort are underestimated (see supplementary figures in data supplement on bmj.com).

\section{Comparisons with other studies}

Recently, a meta-analysis and a pooled analysis summarised the risk of lung cancer associated with household coal burning for heating and cooking, and highlighted the importance of geographical variation. ${ }^{45}$ The results of the present study provide additional evidence that different coal types are associated with different carcinogenicity. Carcinogenic polycyclic aromatic hydrocarbons (PAHs), methylated PAHs, and nitrogen-containing heterocyclic aromatic compounds were found in abundance in the particles emitted from smoky coal combustion. ${ }^{6}$ During combustion, these contaminants are potentially released into the air in their original or oxidised forms. The quality of coal that is used in households around the world varies markedly because of differences in local coal deposits. ${ }^{4}$ The results of our study underline the importance of evaluating the carcinogenic potential of the different types of coal and taking actions to minimise exposure to the most hazardous ones.

\section{Conclusions and policy implications}

The results of this study, which was carried out in a large population with a long period of observation, show that the domestic use of smoky coal is associated with a substantial increase of the lifetime risk of developing lung cancer. This finding has important implications for public health. The use of less carcinogenic types of coal or other fuels can translate into a substantial reduction of lung cancer risk. Additional studies are warranted to better characterise the carcinogenic potentials of various coal types.

We thank the Xuanwei residents who participated in the research. This study would not have been possible without the cooperation of many Chinese administrative and public health officials, physicians, and survey workers.

Contributors: $\mathrm{XH}, \mathrm{QL}$, and RSC designed this study, managed data collection, and participated in data processing. FBA conducted the 


\section{What this already known on this topic}

Coal and biomass fuels are used for household cooking and heating by about 3 billion people worldwide

The risk of lung cancer associated with household coal burning shows a substantial heterogeneity by geographical location because of the use of different coal types

\section{What this study adds}

The domestic use of smoky coal compared with the use of smokeless coal was associated with a more than 30 -fold increase in the risk of developing lung cancer in Xuanwei County in China and is likely to represent one of the strongest effects of environmental pollution reported for cancer risk in any population

Use of less carcinogenic types of coal or alternative fuel sources would translate to a substantial reduction of lung cancer risk

analyses and was primarily responsible for writing the paper under the supervision of QL, and in consultation with RSC. The analysis incorporated suggestions by NR, RV, DTS, JF and QL. All authors contributed to draft manuscripts and the final version. QL and RSC are the guarantors.

Funding: The study was supported by the Chinese Academy of Preventive Medicine, Beijing, China, by the Yunnan Province Antiepidemic Station, Kunming, China, and by contract 5D2290NFFX from the US Environmental Protection Agency. This study was also supported by the Intramural Research Program of the National Cancer Institute, National Institutes of Health. The Xuanwei cohort study has been reviewed by the US Environmental Protection Agency and the National Cancer Institute. The contents do not necessarily reflect the views or policies of these institutions, nor does mention of trade names or commercial products constitute endorsement or recommendation for use. The funding source had no role in design or conduct of the study; collection, management, analysis, or interpretation of the data; preparation, review, or approval of the manuscript.

Competing interests: All authors have completed the ICMJE uniform disclosure form at www.icmje.org/coi_disclosure.pdf (available on request from the corresponding author) and declare: no support from any organisation for the submitted work beyond that already listed; no financial relationships with any organisations that might have an interest in the submitted work in the previous three years; no other relationships or activities that could appear to have influenced the submitted work. Ethical approval: The study was approved by the institutional review board of the Chinese Academy of Preventive Medicine.

Data sharing: No additional data available

1 Smith KR, Samet JM, Romieu I, Bruce N. Indoor air pollution in developing countries and acute lower respiratory infections in children. Thorax 2000;55:518-32.

2 Lan Q, He X, Shen M, Tian L, Liu LZ, Lai H, et al. Variation in lung cancer risk by smoky coal subtype in Xuanwei, China. Int J Cancer 2008;123:2164-9.

3 IARC. Working Group on the evaluation of carcinogenic risks to humans. household use of solid fuels and high-temperature frying. IARC Monogr Eval Carcinog Risks Hum 2010;95:1-430.

4 Hosgood HD 3rd, Boffetta P, Greenland S, Lee YC, McLaughlin J, Seow A, et al. In-home coal and wood use and lung cancer risk: a pooled analysis of the International Lung Cancer Consortium. Environ Health Perspect 2010;118:1743-7.

5 Hosgood HD 3rd, Wei H, Sapkota A, Choudhury I, Bruce N, Smith KR, et al. Household coal use and lung cancer: systematic review and meta-analysis of case-control studies, with an emphasis on geographic variation. Int $J$ Epidemiol 2011;40:719-28.

6 Zhang JJ, Smith KR. Household air pollution from coal and biomass fuels in China: measurements, health impacts, and interventions. Environ Health Perspect 2007;115:848-55.
7 Chen J, Peto R, Pan W, Liu B, Campbell TC. Mortality, biochemistry, diet and lifestyle in rural China. Oxford University Press, 2006 (available free at www.ctsu.ox.ac.uk/ china/ monograph/).

8 Mumford JL, He XZ, Chapman RS, Cao SR, Harris DB, Li XM, et al. Lung cancer and indoor air pollution in Xuan Wei, China. Science 1987;235:217-20.

9 Granville CA, Hanley NM, Mumford JL, DeMarini DM. Mutation spectra of smoky coal combustion emissions in Salmonella reflect the TP5 3 and KRAS mutations in lung tumors from smoky coal-exposed individuals. Mutat Res 2003;525:77-83.

10 Keohavong P, Lan Q, Gao WM, DeMarini DM, Mass MJ, Li XM, et al. K-ras mutations in lung carcinomas from nonsmoking women exposed to unvented coal smoke in China. Lung Cancer 2003;41:21-7.

11 Lan Q, Chapman RS, Schreinemachers DM, Tian L, He X. Household stove improvement and risk of lung cancer in Xuanwei, China. J Natl Cancer Inst 2002;94:826-35.

12 Chapman RS, He X, Blair AE, Lan Q. Improvement in household stoves and risk of chronic obstructive pulmonary disease in Xuanwei, China: retrospective cohort study. BMJ 2005;331:1050.

13 Hosgood HD 3rd, Chapman R, Shen M, Blair A, Chen E, Zheng T, et al. Portable stove use is associated with lower lung cancer mortality risk in lifetime smoky coal users. $\mathrm{Br} J$ Cancer 2008;99:1934-9.

14 Shen M, Chapman RS, Vermeulen R, Tian L, Zheng T, Chen BE, et al. Coal use, stove improvement, and adult pneumonia mortality in Xuanwei, China: a retrospective cohort study. Environ Health Perspect 2009;117:261-6.

15 World Health Organization. International classification of diseases, 1975 revision. WHO, 1977.

16 Coviello $M$ and Boggess $M$. Cumulative incidence estimation in the presence of competing risks. Stata J 2004;4:103-12.

17 Pepe MS, Mori M. Kaplan-Meier, marginal or conditional probability curves in summarizing competing risks failure time data? Stat Med 1993;12:737-51.

18 Grambsch PM, Therneau TM. Proportional hazards tests and diagnostics based on weighted residuals. Biometrika 1994;81:515-26.

19 Royston D, Sauerbrei W. Multivariable modeling with cubic regression splines: a principled approach. Stata J 2007;7:45-70

20 Peto R, Darby S, Deo H, Silcocks P, Whitley E, Doll R. Smoking, smoking cessation, and lung cancer in the UK since 1950: combination of national statistics with two case-control studies. BMJ 2000;321:323-9.

21 Crispo A, Brennan P, Jockel KH, Schaffrath-Rosario A, Wichmann HE, Nyberg F, et al. The cumulative risk of lung cancer among current, ex- and never-smokers in European men. Br J Cancer 2004;91:1280-6.

22 Lee KM, Chapman RS, Shen M, Lubin JH, Silverman DT, He X, et al. Differential effects of smoking on lung cancer mortality before and after household stove improvement in Xuanwei, China. Br J Cancer 2010;103:727-9.

23 Lubin JH, Qiao YL, Taylor PR, Yao SX, Schatzkin A, Mao BL, et al. Quantitative evaluation of the radon and lung cancer association in a case control study of Chinese tin miners. Cancer Res 1990;50:174-80.

24 Taylor PR, Qiao YL, Schatzkin A, Yao SX, Lubin J, Mao BL, et al. Relation of arsenic exposure to lung cancer among tin miners in Yunnan Province, China. Br J Ind Med 1989;46:881-6.

Accepted: 25 July 2012

\section{Cite this as: BMJ 2012;345:e5414}

This is an open-access article distributed under the terms of the Creative Commons Attribution Non-commercial License, which permits use, distribution, and reproduction in any medium, provided the original work is properly cited, the use is non commercial and is otherwise in compliance with the license. See: http://creativecommons.org/licenses/by$\mathrm{nc} / 2.0 /$ and http://creativecommons.org/licenses/by-nc/2.0/legalcode 


\section{Tables}

Table 1 | Characteristics of cohort members in study of mortality from lung cancer among lifelong users of "smoky coal" (bituminous) and "smokeless coal" (anthracite) in household stoves in Xuanwei County 1976-96. Values are numbers (percentages) of participants unless stated otherwise

Men Women

Smoky coal $(n=14$ 232) Smokeless coal $(n=5418)$

Smoky coal $(n=13$ 078) Smokeless coal $(n=4544)$

No of person years 261102 102467 239728

Mean (SD) age at 1 January 1976 (years)

$39.1(10.5)$

$39.9(10.9)$

$38.5(10.5)$

$56.0(9.4)$

Mean (SD) age at exit from follow-up (years)

$56.7(9.5)$

$57.6(9.8)$

$9706(74)$

Alive at the end of follow-up

$10492(74)$

$4318(80)$

$43(0.3)$

87621

$13102(92)$

5031 (93)

$12784(98)$

$6885(48)$

$304(6)$

3232 (25)

With any education

$11849(83)$

2321 (43)

10929 (84)

$1081(8) \quad 20(0.4)$

Ever worked as a miner

$5.2(1.7)$

Mean (SD) household size over lifetime

$1.6(0.9)$

$5.3(1.7)$

$24(0.2)$

Mean (SD) number of rooms in home over

$7.0(2.2)$

$2.0(1.0)$

$5.3(1.6)$

$1.6(0.9)$

$5.9(2.0)$

$7.6(2.3)$

(hours) $^{*}$

*Excluding time spent sleeping. 
Table 2| Deaths from lung cancer among individuals aged less than 70 years in Xuanwei cohort 1976-96, stratified by type of coal used in household stoves ("smoky coal" (bituminous) or "smokeless coal" (anthracite)), sex, and smoking habit

\begin{tabular}{|c|c|c|c|c|}
\hline \multirow[b]{2}{*}{ Sex and smoking status } & \multicolumn{2}{|c|}{ Smoky coal } & \multicolumn{2}{|c|}{ Smokeless coal } \\
\hline & No of cases/group & Mortality $(95 \% \mathrm{Cl})^{*}$ & No of cases/group & Mortality $(95 \% \mathrm{Cl})^{*}$ \\
\hline \multicolumn{5}{|l|}{ Men: } \\
\hline Never smoked & $88 / 1130$ & 450 (355 to 545$)$ & $0 / 387$ & NA \\
\hline Ever smoked & $1067 / 13102$ & 488 (459 to 518$)$ & $12 / 5031$ & 13.1 (5.70 to 21.1$)$ \\
\hline \multicolumn{5}{|l|}{ Women: } \\
\hline Never smoked & $1124 / 13035$ & 527 (496 to 558$)$ & $4 / 4536$ & $4.7(1.0$ to 9.4$)$ \\
\hline Ever smoked & $2 / 43$ & NA & $0 / 8$ & NA \\
\hline
\end{tabular}

*Age standardised mortality per 100000 person years. The age structure of the group of smokeless coal users ( $n=9962)$ was used as the standard population. 
Table 3| Effect of lifelong use of different types of coal in household stoves ("smoky coal” (bituminous) or "smokeless coal” (anthracite)) on risk of death from lung cancer in Xuanwei cohort 1976-96, stratified by sex

\begin{tabular}{lcc} 
& & Hazard ratio (95\% Cl) \\
\cline { 2 - 3 } Sex and coal used & Unadjusted & Adjusted $^{*}$ \\
Men: & 1 (reference) & 1 (reference) \\
\hline Smokeless coal & $41.6(23.6$ to 73.5$)$ & $36.2(20.3$ to 64.7$)$ \\
\hline Smoky coal & & 1 (reference) \\
\hline Wmomen: & $115.8(43.4$ to 309.0$)$ & $98.8(36.8$ to 265.6) \\
\hline Smoky coal &
\end{tabular}

*Hazard ratios are adjusted for type of stove used, time spent at home each day (excluding sleeping), having any formal education, number of rooms in home, number of people in home, family history of lung cancer, prior diagnosis of chronic respiratory diseases, and sex-specific adjustments (having smoked tobacco and history of employment as a coal miner for men; age at which person started cooking for women). Baseline hazards are stratified by birth cohort. 


\section{Figures}
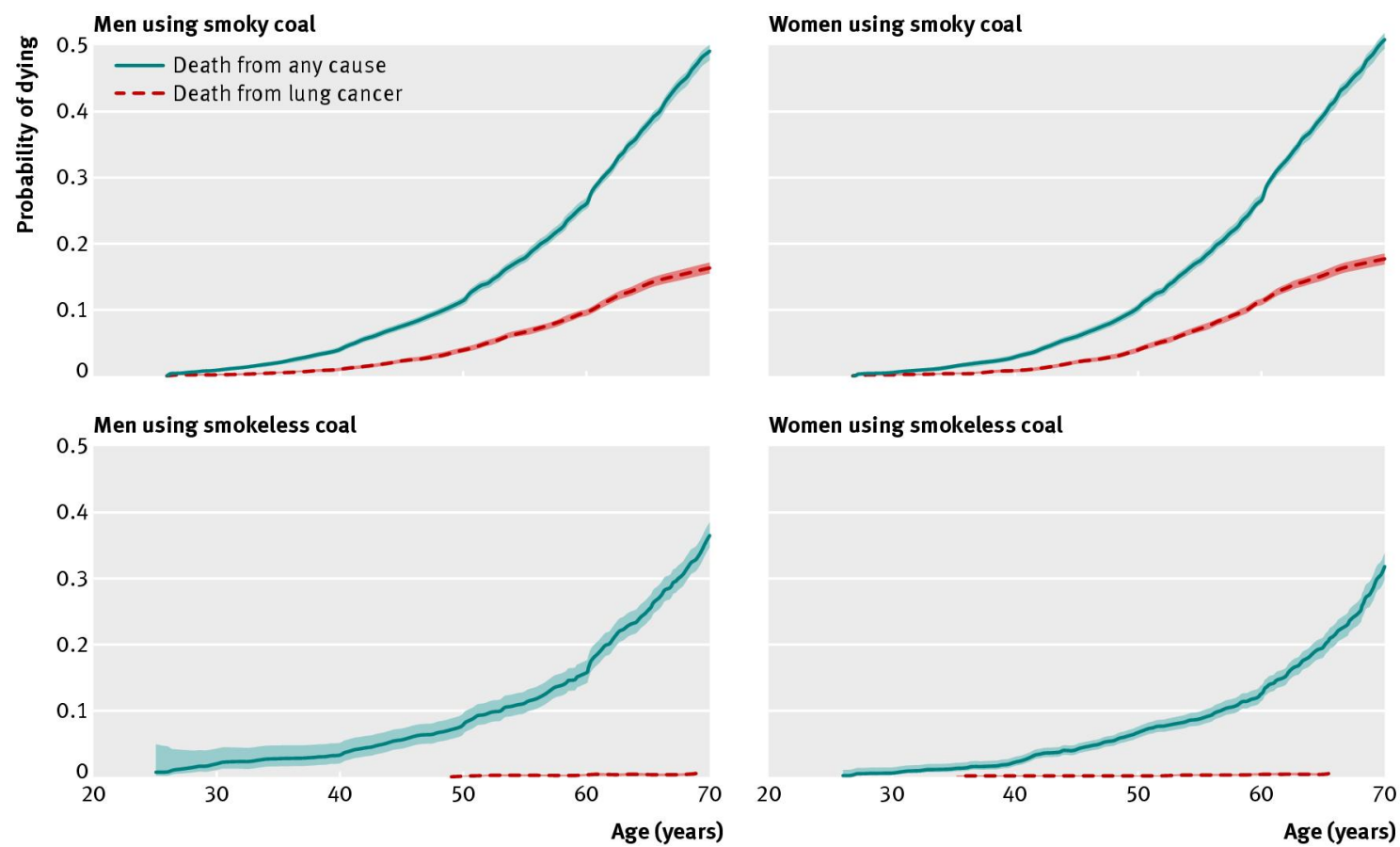

Fig 1 Unadjusted survival analysis in Xuanwei cohort 1976-96: cumulative risk (95\% Cl) of death from any cause and of death from lung cancer by age, stratified by type of coal used in household stoves and sex

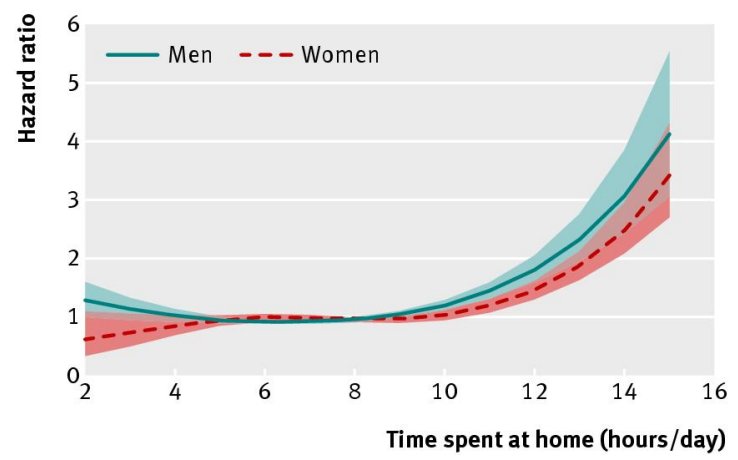

Fig 2 Association between mean time spent indoors at home each day (excluding sleeping) and risk of death from lung cancer among users of smoky coal in household stoves in Xuanwei cohort 1976-96. (Hazard ratios (95\% Cl) are adjusted for type of stove used, having any formal education, number of rooms in home, number of people in home, family history of lung cancer, prior diagnosis of chronic respiratory diseases, and (men only) having smoked tobacco) 


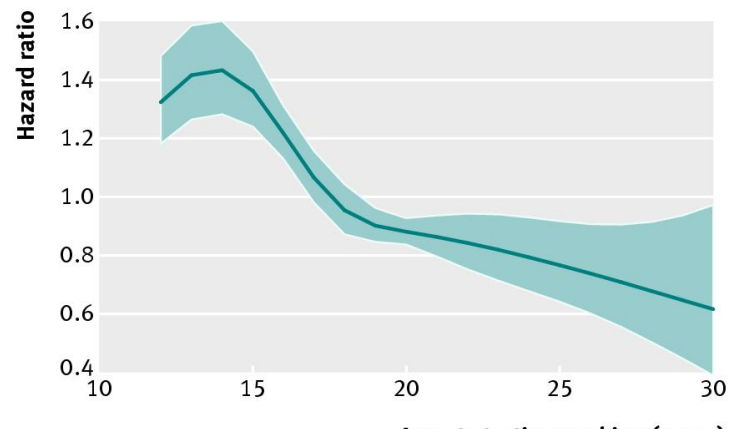

Fig 3 Association between age when participant started cooking and risk of death from lung cancer among women using smoky coal in household stoves in Xuanwei cohort 1976-96. (Hazard ratios (95\% Cl) are adjusted for time spent indoors at home each day (excluding sleeping), type of stove used, having any formal education, number of rooms in home, number of people in home, family history of lung cancer, and prior diagnosis of chronic respiratory diseases) 